
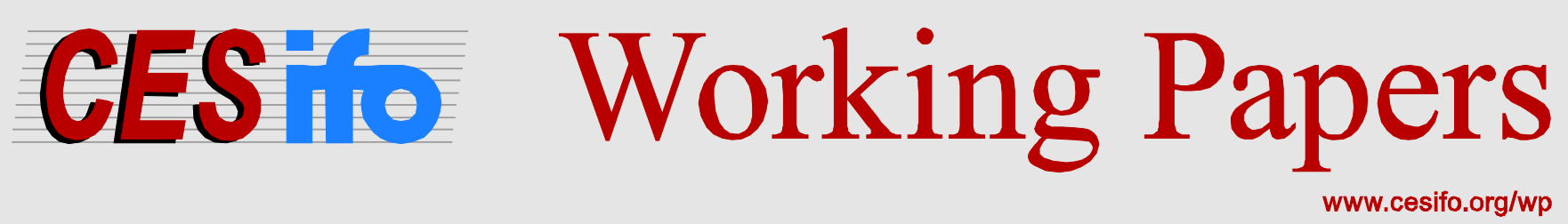

\title{
Who Cares for Social Image? Interactions between Intrinsic Motivation and Social Image Concerns
}

\author{
Jana Friedrichsen \\ Dirk Engelmann
}

CESIFO WORKING PAPER NO. 4514

CATEGORY 13: BEHAVIOURAL ECONOMICS

DECEMBER 2013

Presented at CESifo Area Conference on Behavioural Economics, October 2013

An electronic version of the paper may be downloaded

- from the SSRN website:

- from the RePEc website:

- from the CESifo website:

wWw.SSRN.com

www.RePEc.org

www.CESifo-group.org/wp

\section{CESifo}




\title{
Who Cares for Social Image? Interactions between Intrinsic Motivation and Social Image Concerns
}

\begin{abstract}
We consider the interaction of intrinsic motivation and concerns for social approval in a laboratory experiment. We elicit a proxy for Fairtrade preferences before the experiment in which we elicit willingness to pay for conventional and Fairtrade chocolate. Treatments vary whether this can be signaled to other participants. Subjects concerned with social approval should state a higher Fairtrade premium when signaling is possible. We find that this is the case, but interestingly only for participants who are not intrinsically motivated to buy Fairtrade. This has important implications both for crowding out of intrinsic motivation through incentives and for producer choices.
\end{abstract}

JEL-Code: D030, C910.

Keywords: image concerns, Fairtrade, ethical consumption, crowding out, experiments.

\author{
Jana Friedrichsen \\ WZB \\ Reichpietschufer 50 \\ Germany - 10785 Berlin \\ jana.friedrichsen@wzb.eu
}

\author{
Dirk Engelmann* \\ Department of Economics \\ University of Mannheim \\ L7, 3-5 \\ Germany - 68131 Mannheim \\ dirk.engelmann@uni-mannheim.de
}

*corresponding author

November 26, 2013

We thank M’Hamed Helitim, Steffen Huck, Heiko Karle, Georg Kirchsteiger, Tatiana Kornienko, Rosemarie Nagel, Charlie Plott, Nora Szech, Mirko Tonin, Bertil Tungodden, Joël van der Weele, and Christian Waibel as well as seminar participants at the University of Cologne, Humboldt-University Berlin, Paris I - Sorbonne, the University of Marburg, the Berlin Behavioral Economics workshop, and at the International ESA conference 2012 in New York, the European ESA conference 2012 in Cologne, the annual meeting of the Gesellschaft für experimentelle Wirtschaftsforschung 2012 in Karlsruhe, the HeiMaX workshop 2012 in Heidelberg, the Spring Meeting of Young Economists 2013 in Aarhus, the Journées Louis-André Gérard-Varet 2013 in Aix-enProvence, EEA-ESEM 2013 in Gothenburg, EARIE 2013 in Evora, the annual meeting of the Verein für Socialpolitik 2013 in Düsseldorf, and the CESifo Area Conference on Behavioral Economics 2013 for helpful comments and suggestions. 


\section{Introduction}

Empirical research suggests that choices for products considered to be ethical are driven not only by intrinsic motivation but also by concerns for social approval (Griskevicius et al., 2010; Sexton and Sexton, 2011). How intrinsic motivation and image concerns interact is important for supply and pricing policy of these products (Friedrichsen, 2013). Furthermore, the interaction is relevant to assess potentially negative effects of incentives on behavior motivated by intrinsic motivation or image concerns (Bénabou and Tirole, 2006; Gneezy and Rustichini, 2000; Seabright, 2009). Specifically, if those who are intrinsically motivated are little concerned with the image derived from their choices, then encouraging others through incentives to make the same choice would not lead to crowding out of intrinsically motivated behavior. Instead, if those intrinsically motivated also tend to care a lot for the image they derive from their choice, pooling by those who are only motivated through extrinsic incentives would lead the former to derive less utility from their ethical choices and thus potentially to crowding out.

However, little is known about this interaction between intrinsic motivation and concerns for social approval from empirical work. Due to this lack of empirical evidence, we assess in a laboratory experiment, how intrinsic motivation and social image concerns interact in the context of Fairtrade products. In particular, we try to find out whether intrinsically motivated individuals react more or less strongly to opportunities for image building than other individuals.

A growing number of empirical and experimental studies support the assumption that individuals exhibit status or image seeking behavior. ${ }^{1}$ Social approval or image seeking is often explained by appealing to evolutionary arguments (in particular sexual selection by mate choice): individuals who are perceived as better types have superior matching possibilities and thus increased chances of reproduction and healthy descendants (Miller, 2000; De Fraja, 2009). Similarly, status concerns may evolve as an equilibrium phenomenon in a context where interactions are complementary in the partners' unobservable abilities of which status is an observable signal (Rege, 2008). Similar to demonstrating wealth, engaging in pro-social or pro-environmental behavior can signal one's willingness and ability to take costly action to a potential partner's benefit (Griskevicius et al., 2007).

\footnotetext{
${ }^{1}$ For theoretical studies on the impact of status or image concerns on product design, pricing and advertising see e.g. Ireland (1994); Pesendorfer (1995); Bagwell and Bernheim (1996); Pastine and Pastine (2002); Rayo (2013) and the early contribution by Veblen (1915).
} 
The majority of empirical studies on image concerns in purchasing behavior relate to conspicuous consumption where consumers desire to signal their wealth through their purchases (Chao and Schor, 1998; Charles et al., 2009; Heffetz, 2011). In addition, image concerns have received substantial attention in the context of pro-social behavior. In particular, it has been shown that blood donations (e.g. Lacetera and Macis, 2010) and alumni giving (e.g. Harbaugh, 1998a,b) are partly motivated by reputational concerns but similarly volunteer fire-fighting (Carpenter and Myers, 2010), volunteering (Linardi and McConnell, 2011), and effort provision for charity (Ariely et al., 2009) are reported to be related to image concerns.

As green or ethical consumption have grown fashionable, new studies indicate that these too go together with image concerns in the sense that consumers' purchasing behavior is affected by a desire to appear as a pro-social, ethical, or environmentally-friendly shopper instead of or complementary to signaling pure wealth. Using data on car purchases, Sexton and Sexton (2011) find that "consumers are willing to pay up to several thousand dollars to signal their environmental bona fides through their car choices". The car which is used to signal is the Toyota Prius, which according to market research is a conspicuously green car (Maynard, 2007). Complementary evidence on social image concerns in ethical consumption is provided in Griskevicius et al. (2010). In a series of lab experiments they find that priming subjects with status motives increased their desire to purchase green products in public but not in private. ${ }^{2}$ We discuss further relevant experimental studies on image concerns, which often employ (modified) dictator games, as well as other related experiments in the next section.

While there is thus substantial evidence on the existence of image concerns, we are not aware of any study formally investigating the important heterogeneity of image concerns with respect to intrinsic motivation. In Section 5, however, we discuss some results, which are consistent with heterogeneity in image concerns, even though this is not explicitly addressed in the respective studies.

Our experiment explicitly addresses the interaction of intrinsic pro-social motivation and concerns for social image. Before subjects come to the experiment, we elicit a proxy for their intrinsic motivation for Fairtrade chocolate by simply offering a choice between Fairtrade and conventional chocolate as an additional reward for taking part in the experiment. In the experiment itself, participants first engage in a market game unrelated to chocolate or Fairtrade products. Then we elicit in an incentive compatible way the

${ }^{2}$ Note that in all these examples the behavior cannot be explained by a signaling desire alone in a Bayesianrational model, since the signaling only makes sense if some individuals actually are pro-social. 
willingness to pay both for conventional and Fairtrade chocolate and thus can derive for each individual subject a Fairtrade premium they are willing to pay. Our treatments vary whether the willingness to pay is kept private or has to be announced publicly and thus whether participants can build an image among the fellow participants for being concerned with Fairtrade. In a questionnaire, we also ask about knowledge about and attitudes towards Fairtrade and confirm that the latter are quite positive, so that our variation of image building opportunities indeed allows participants to derive a positive social image.

We find that subjects who have not revealed an intrinsic motivation for Fairtrade before the experiment exhibit a significantly larger Fairtrade premium with image building opportunities than without, whereas those who chose Fairtrade before the experiment do not react significantly to these opportunities. Hence in our experiment intrinsic motivation and image concerns are negatively correlated. This result has important implications in two areas. The first regards the optimal design of product portfolios. The second concerns the crowding out of intrinsically motivated socially beneficial behavior through incentives that encourage those not intrinsically motivated. We discuss these implications in Section 5. Before that, we discuss related experimental results in Section 2, present the experimental design and procedures in detail in Section 3 and the experimental results in Section 4.

\section{Experimental results on image concerns}

A number of experimental studies provide evidence on the existence of image concerns in the context of pro-social behavior. Assuming that behaving pro-socially confers a positive image, image-concerned individuals should behave more pro-socially in the public sphere than in private. Experimental investigations of giving in the laboratory (Andreoni and Bernheim, 2009; Grossman, 2010; Lazear et al., 2012; Tonin and Vlassopoulos, 2013; Frackenpohl and Pönitzsch, 2013) and in the field (Soetevent, 2005, 2011; DellaVigna et al., 2012) are consistent with this prediction even though the authors do not necessarily put forward image concerns as an explanation for their results and other explanations are possible as well. More specifically, DellaVigna et al. (2012) distinguish joy from giving and social pressure as motivations for giving in a field experiment. The effect of social pressure on giving is very similar to that of concerns for social or self image, but the welfare implications differ.

Soetevent (2011) finds that contribution and participation rates in door-to-door fundraising drop severely when participants can donate only using a debit card instead of 
having the option to donate in cash. However, contributing households in the debit-only treatment are more generous. Both findings are consistent with image concerns. As the author argues, a crucial point is that the amount donated is visible when donating by card whereas with cash donations only the fact of giving is observed. ${ }^{3}$ These findings could, however, also be due to differences in the payment types (with some people indeed not having a card at hand and the others being simply the more generous households). Similarly, Soetevent (2005) finds a positive effect of using open baskets for church offerings for external causes instead of closed collection bags but cannot disentangle an image effect from an asymmetric information effect. The latter takes place if the quality of a cause is unknown and the first mover can increase other people's donations by signaling her private information through the size of her gift. ${ }^{4}$

In a further laboratory experiment, Andreoni and Bernheim (2009) find that giving in a dictator game is subject to "audience effects", where audience effects mean that individuals tailor their behavior to conforming with a perceived norm of "good" behavior. Grossman (2010) points out, however, that these results would also obtain if individuals wanted to signal to themselves and not to the audience. Thus, he extends the framework of Andreoni and Bernheim (2009) to investigate the relative importance of social signaling (audience effects) versus self-signaling. The results of Grossman (2010) indicate that self-signaling does not play a major role for giving in a dictator game but social signaling is a relevant motivation for a large subsample of individuals.

Findings from dictator games with sorting options (Lazear et al., 2012) can be related to (self-) image concerns as well, even though the authors do not discuss this. "Reluctant sharers" who are most generous in a standard dictator game are least willing to re-enter the dictator game when the sharing environment is increasingly subsidized. Image concerns (as well as social pressure) can explain why individuals give generously if they have to give something but prefer to avoid the giving situation. Image concerns (but less so social

\footnotetext{
${ }^{3}$ Note also that donating being only possible by card gives people the option of pretending to have security concerns, while in turn the lower donation rate increases the return on donations in terms of image, making larger donations more attractive. This would also suggest that debit donors in the debit-only treatment donate more than debit donors in the treatment with cash and debit options. This hypothesis, however, cannot be tested since only three donors (out of 444 who contributed) chose to use a card when the option to give in cash was available.

${ }^{4}$ This asymmetric information channel has been analyzed explicitly for instance in Vesterlund (2003) and Potters et al. (2007). In a similar vein, the positive audience effects found by Linardi and McConnell (2011) in a laboratory experiment on volunteering could be explained by participants increasing their own effort to influence their peers to also work more.
} 
pressure) also explain why these individuals are reluctant to enter a subsidized dictator game because the subsidy distorts the signaling value of giving (Bénabou and Tirole, 2006). ${ }^{5}$

While the above studies use making choices public as a trigger for image concerns, Tonin and Vlassopoulos (2013) find evidence for self-image concerns in dictator games without manipulating the visibility of actions. When given the option to ex post exit the dictator game, a significant fraction of participants took this up and kept the whole amount - an option that had been available already in the dictator game. Deciding to give a positive amount and then stepping back from this pro-social behavior ex post is consistent with self-image concerns because decisions were made for three dictator games only one of which was randomly chosen to be implemented.

Our use of Fairtrade products to elicit image concerns also puts us in close relation to the literature on impure public goods and ethical differentiation, because Fairtrade products are similar to those that bundle a conventional product with a donation. Valente (2010) tests in class room experiments the effects of bundling a donation to Oxfam with a purchase of chocolates and finds that the presence of such an impure public good leads to lower overall donations. ${ }^{6}$ She also finds that some participants even choose inefficient bundles (i.e., where the price difference to the conventional good is larger than the donation). Apparently, when a product with a bundled-in donation is offered, subjects perceive this level as appropriate to derive a positive self-image. In contrast, Koppel and Schulze (2013) find in a field experiment that donations are higher if they are bundled with a private good (beverages in coffee shops in their case), even if the level of donation can be chosen. Social image concerns may matter here because if the donations are bundled with the product, the consumers have to communicate their choices to the staff, whereas direct donations are just dropped into a box (this is one of the explanations discussed by their authors, though not explicitly linked to image concerns). The findings by Frackenpohl and Pönitzsch (2013) support self-image concerns in an experiment on the willingness to pay for public goods. They find that bundling a private and a public good increases the valuations for both the public and the private good. One of several explanations discussed by the authors are selfimage concerns. By design, concerns for social image cannot explain their findings because

\footnotetext{
${ }^{5}$ Also "costly (but quiet) exit in dictator games" is a possible effect of image concerns. If I want you to think good of me, this is an image concern. In the experiments by Dana et al. (2006) visibility is not manipulated in making a person and her action visible to another but by revealing or disclosing that a certain outcome is related to another individual's action.

${ }^{6}$ The use of chocolate is popular in experiments using real goods, probably because "Nine out of ten people like chocolate. The tenth person always lies." (John Q. Tullius, who is apparently known primarily for this quote).
} 
choices are made in private. Strahilevitz and Myers (1998) investigate bundling necessary goods and "frivolous luxuries" with charitable donations in laboratory experiments and field studies. Their interest lies in the marketing aspect of this bundling and they find that it is a more effective marketing tool for "frivolous luxuries". This might be the case because the charitable donations enhance the self-image, which is otherwise damaged by the luxury purchase. Alternatively, the higher visibility of the luxury good enhances the possibility of communicating the donation. This in turn makes the donation and thereby the bundle more valuable in terms of image.

Our experiment has been designed independently and simultaneously to a study on social and self-image concerns in Fairtrade consumption by Teyssier et al. (2012) using a similar design. In contrast to their study, our main interest is not in the existence but the possible heterogeneity of image concerns. While they find - in line with our results that the willingness to pay a premium for Fairtrade is higher in public, the driving forces behind this aggregate finding appear to differ (see discussion in Section 5).

\section{$3 \quad$ Experimental design and procedures}

Our experimental design consists of three steps. First, after participants have registered for the experiment, but before they arrive at the laboratory, we derive a proxy for their preference for Fairtrade products. Second, in the first part of the laboratory experiment, they take part in a market game. Third, in the second part of the laboratory experiment, we elicit their willingness to pay for Fairtrade and conventional chocolate with an incentive compatible random price mechanism, where our treatments vary the possibility for image building. Our main interest here lies in the relation between the intrinsic motivation elicited before the experiment and the reaction to image building opportunities varied in the second part of the experiment. The market game serves two purposes. On the one hand, given that the second part is short, we used the opportunity to assess the generalizability of fair

behavior observed in an experimental labor market by comparing behavior in this market with Fairtrade choices both before the experiment and in its second part. This analysis is the focus of a companion paper (Danz et al., 2013). On the other hand, the market game serves to start the experiment in a relatively conventional fashion and thus removes the focus from the rather unusual chocolate purchase in the second part.

In order to derive a proxy for their intrinsic preference for Fairtrade products we offered subjects via email the choice between Fairtrade and conventional milk chocolate as an 
additional reward for coming to the experiment. This email was sent and had to be answered before they came to the laboratory but chocolate was distributed only after the experiment. Since Fairtrade chocolate is in general more expensive, we offered a choice between a slightly larger (125g) bar of conventional chocolate and standard size (100g) bar of Fairtrade chocolate.

For a number of reasons, this proxy is noisy. First of all, subjects might be motivated to build an image towards the experimenters. As a result, some of those whom we classify as intrinsically motivated might be rather concerned with their image in the eyes of the experimenter. Second, Fairtrade products might simply be perceived as of higher quality. Hence some of those choosing Fairtrade chocolate might not be concerned with the production methods, but just expect a large quality difference. ${ }^{7}$ Third, because in our first sessions only few subjects chose the conventional chocolate (even though the choices were more balanced when we used the same chocolate for recruiting new subjects), we offered a choice between two bars of conventional chocolate and one bar of Fairtrade chocolate in the following sessions. We balanced the design with respect to whether we offered one or two bars of conventional chocolate. Interestingly, a majority still chose Fairtrade, probably because the two-to-one choice was perceived as a signal that the Fairtrade chocolate was substantially more expensive than the conventional chocolate, which is actually not true (the price for a bar of conventional chocolate was $0.95 €$, for the Fairtrade chocolate $1.29 €$. $)^{8}$ For these reasons, our classification into Fairtrade and conventional choosers is noisy. This should, however, only reduce any differences we find between these two groups in terms of attitudes and behavior because, while the proxy is noisy, it is not systematically biased.

Note that an experimenter demand effect in the sense that subjects choose Fairtrade chocolate or inflate their willingness to pay to impress us as experimenters is not problematic for the question we are interested in. We are interested in who reacts to opportunities to build a social image. If subjects care about their image in the eyes of the experimenter, this would increase their willingness to pay in all treatments. Nevertheless, as long as they also care about their image in the eyes of the other participants, our treatment vari-

\footnotetext{
${ }^{7}$ Indeed, survey responses show that in addition to pro-social motivations, quality expectations do play a role for choosing Fairtrade (see Table 3 in the Appendix). This does not invalidate our analysis though. Even if subjects were only interested in quality and not pro-sociality a modified story holds where some care more about quality than others and these groups react differently to the image building opportunity in the public treatment. Moreover, we confirmed that our results as reported below do not change if we control for two measures of quality perceptions.

${ }^{8}$ Our own evaluation of the taste did not reveal any difference either way.
} 
ation would affect their behavior. Our results indicate that image concerns induced by our treatment as outlined below are not outweighed by reputational concerns towards the experimenters. A similar argument applies if subjects believed the choice of chocolate taking place earlier was part of the experiment and chose Fairtrade strategically since they probably did so because it was good for their image. ${ }^{9}$

The laboratory experiment itself consists of two parts. In the first part, the participants take part in a market game modified from Danz et al. (2012), with participants taking the roles of firms, consumers and workers. In the second part, we elicit from each participant his or her willingness-to-pay (between 0-2€) for both Fairtrade and conventional dark chocolate $\left(\mathrm{WTP}_{\text {fair }}\right.$ and $\left.\mathrm{WTP}_{\text {conv }}\right)$ using a random price mechanism (Becker et al., 1964). Specifically, subjects enter a price between 0 and 2 Euros, where any multiple of $0.01 €$ was permitted. Then we draw a price from a uniform distribution of all integer multiples of $0.01 €$. Subjects receive a bar of the chocolate type sold if their stated WTP for that type is at least as high as the randomly chosen price. Which type of chocolate is sold is determined randomly after the price has been chosen such that the mechanism is incentive compatible for both types of chocolate. We chose dark chocolate for this part of the experiment instead of milk chocolate, so that subjects could not end up with two bars of the same chocolate, which could have reduced their willingness to pay for the type of chocolate of which they were already sure to receive one bar. ${ }^{10}$ We also did not choose any well-known brands, in order to minimize the chance that subjects' willingness to pay was based on taste preferences due to personal experience. ${ }^{11}$ From these two WTPs we infer individuals' willingness' to pay a premium for the Fairtrade chocolate as $\mathrm{WTP}_{\text {premium }}=$ $\mathrm{WTP}_{\text {fair }}-\mathrm{WTP}_{\text {conv }}$.

Our two treatments differ in whether the WTPs are elicited publicly or in private. In treatment private, individuals enter their WTPs privately at the computer. In treatment public, after they have entered their WTPs privately at the computer, all subjects stand up and announce their WTPs publicly among the group of participants. The difference in

\footnotetext{
${ }^{9}$ If one is further worried about a demand effect in the sense that some subjects state a higher willingness to pay in the public treatment because they think we expect them to impress their fellow participants, one has to find a plausible story why intrinsic motivation for Fairtrade is correlated with responding to this demand since we find such a heterogeneity (see Section 4). For instance, subjects who are concerned with their image in the eyes of the experimenters (the authority) might care less about reputation within their peer group and vice versa.

${ }^{10}$ Interestingly, at the time of payment, most of our participants had already forgotten that for participating they would receive a milk chocolate bar of a type chosen beforehand.

${ }^{11} \mathrm{~A}$ picture of the type of chocolate bars which we used in the experiments can be found in the Appendix, Figure 3.
} 
$\mathrm{WTP}_{\text {premium }}$ between the treatments serves as our measure for image concerns. We note that while the random price mechanism (Becker et al., 1964) is incentive compatible in theory, it has been pointed out that experimental subjects may misconceive this mechanism (Plott and Zeiler, 2005; Cason and Plott, 2012). Such misconceptions should be of much less concern in our experiment. Misconceptions appear to be more of an issue for elicitation of willingness to accept to forego an item rather than for willingness to pay to obtain an item. More importantly, we are only interested in $\mathrm{WTP}_{\text {premium, }}$ and in particular in the question whether this differs significantly across groups or treatments. Tests of the related hypotheses are robust to any misconception that only leads to a bias that is monotone in the true WTP and is not systematically correlated with the treatment or subject group.

After entering their WTPs (but before they announce them in public), subjects fill in an extensive questionnaire regarding their attitudes towards and knowledge about Fairtrade. The answers to this questionnaire allows us to confirm the validity of our proxy for intrinsic motivation as those who chose Fairtrade chocolate are more frequent to report to buy Fairtrade products and less frequent to agree to negative statements regarding Fairtrade (see Figure 4 in the Appendix).

The experiment was computerized using zTree (Fischbacher, 2007) and took place in the experimental economics laboratory mLab at the University of Mannheim in May, June, and October 2012. Participants were recruited using ORSEE (Greiner, 2004). An English translation of the (German) instructions for the second part of the experiment is included in the Appendix. We have conducted 8 sessions with 16-20 participants each so that we had in total 144 participants. For part 1 of the experiment, each participant got a show-up fee of $5 €$; for the second part, everyone got an additional endowment of $4 €$. Average cash earnings were $18.63 €$ in total, including the show-up fee and the endowment in the second part, subtracting payments for chocolate if applicable. ${ }^{12}$ In the second part, the payoffrelevant chocolate turned out to be conventional and Fairtrade in half of the sessions each. Details about the (randomly chosen) prices at which chocolates were sold are collected in Table 1. In total, we handed out conventional chocolate to 22 subjects and Fairtrade chocolate to 21 subjects.

${ }^{12}$ In the market game in the first part of the experiment, participants in the role of firms earned $4.50 €$ on average, those in the role of workers earned $6.31 €$ on average, and those in the role of consumers earned $23.73 €$ on average. 


\begin{tabular}{l|rrrr|rrrr}
\hline & \multicolumn{4}{|c|}{ conventional } & \multicolumn{4}{c}{ Fairtrade } \\
\hline price in $€$ & 0.26 & 0.27 & 0.97 & 1.85 & 0.25 & 1.01 & 1.20 & 1.78 \\
treatment & public & private & private & public & public & private & public & private \\
\#participants & 16 & 16 & 20 & 20 & 16 & 16 & 20 & 20 \\
\#bars sold & 11 & 9 & 2 & 0 & 12 & 2 & 7 & 0 \\
\hline
\end{tabular}

Table 1: Prices drawn and number of chocolate bars paid out to participants.

\section{Experimental results}

Our analysis evaluates decisions from 121 subjects who made their choice between Fairtrade and conventional chocolate via email as described above. In addition, 23 newly recruited subjects participated in our experimental sessions but are not included in the analysis. For these subjects, the chocolate choice which we intended to use as a proxy for their intrinsic preference had to be taken in public during a recruitment dayand not via email. We believe that this led to image concerns biasing their choices already at that stage so that we cannot pool them with the other participants. ${ }^{13}$ Unfortunately out of 222 new recruits, only 23 ever showed up in one of our experiments and their chocolate choices are not balanced across treatments such that we cannot hope for reliable results for this subgroup. We therefore exclude these 23 observations from our analysis.

Of the 121 subjects who made their choice via email, 32 chose conventional chocolate, while the remaining 89 chose Fairtrade before coming to the lab. Our main interest lies in whether there is heterogeneity with respect to image concerns along the dimension of intrinsic motivation. We thus compare our measure of image concerns (namely the difference in $\mathrm{WTP}_{\text {premium }}$ between the public and the private treatment) for the two groups of individuals who chose Fairtrade or conventional chocolate before coming to the experiment, respectively. The difference-in-differences in the Fairtrade premium (i.e. the difference in the treatment effect) between the groups of participants shows whether image concerns interact with our measure of intrinsic motivation.

\footnotetext{
${ }^{13}$ Specifically, we had used chocolate as an incentive to sign up to the subject pool in a recruitment drive at the university cafeteria and library. Our original plan was to use the newly recruited subjects in our experiment and their chocolate choice in the recruitment drive as their preference proxy. As it turned out, many of them made their choice in the presence of friends and hence image concerns already had an influence at that stage. Furthermore, very few of them ever signed up to an experiment. Hence incentives worked, but precisely to get them to do what they were incentivized for, namely signing up for the subject pool, but not for taking part in experiments. Further issues are that because they are newly recruited, they are more likely to be confused in the experiment and that they are less likely to know other students in their session and hence less affected by image concerns in the public treatment.
} 

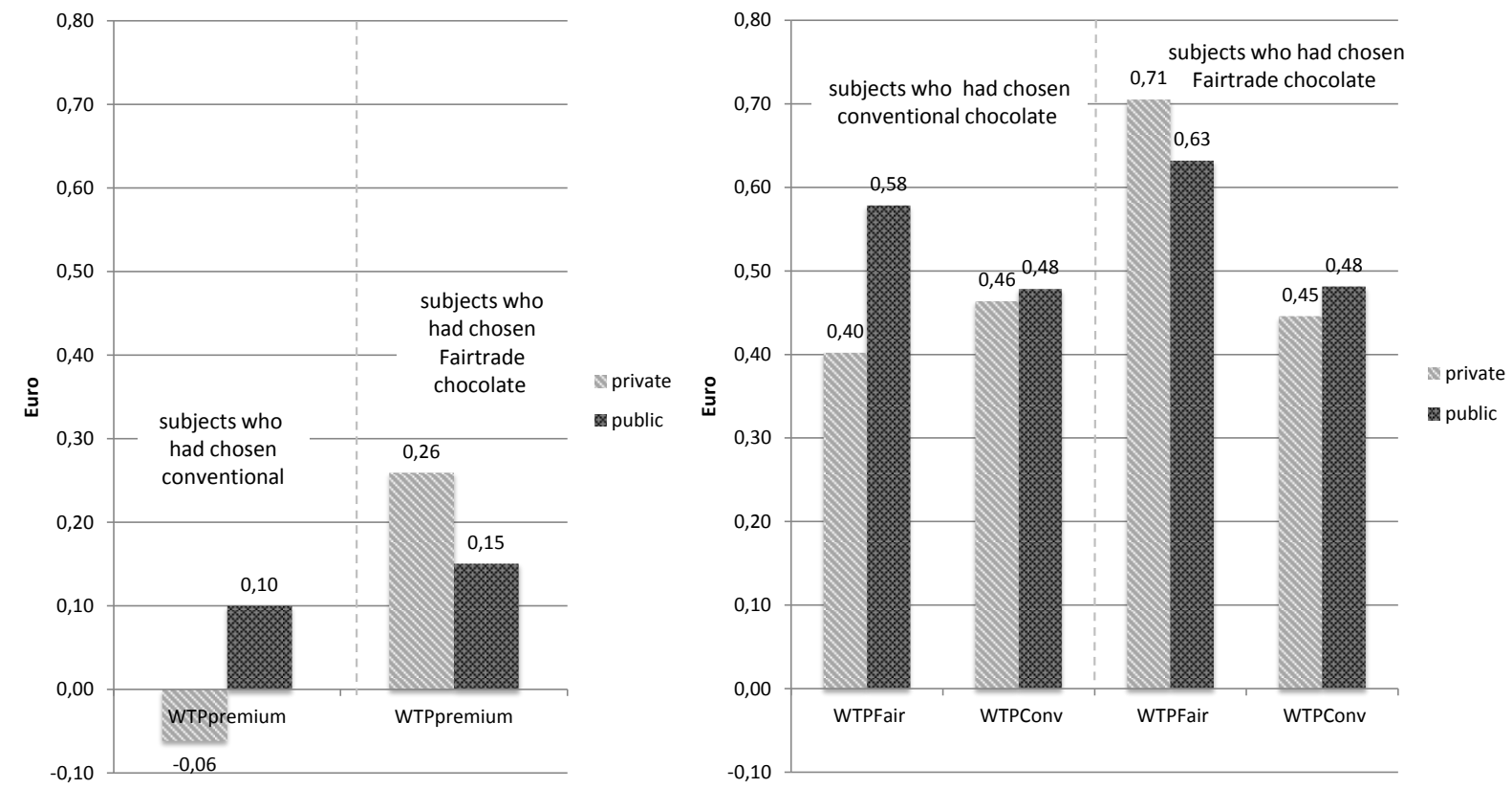

Figure 1: Averages of WTP by treatment and by chocolate choice. Left panel: averages of premium in willingness to pay for Fairtrade, right panel: averages of willingness to pay for Fairtrade and conventional chocolate.

Looking at the averages across individuals (see Figure 1), we see that making choices public increases $\mathrm{WTP}_{\text {fair }}$ from $0.40 €$ to $0.58 €$ and $\mathrm{WTP}_{\text {premium }}$ from $-0.06 €$ to $0.10 €$ for those subjects who had chosen the conventional chocolate. However, it decreases $\mathrm{WTP}_{\text {fair }}$ from $0.71 €$ to $0.63 €$ and $\mathrm{WTP}_{\text {premium }}$ from $0.26 €$ to $0.15 €$ for those who had chosen Fairtrade chocolate. Due to the negative effect on fair-minded individuals and that group being larger, making choices public decreases the average $\mathrm{WTP}_{\text {fair }}$ from $0.63 €$ to $0.62 €$ and $\mathrm{WTP}_{\text {premium }}$ from $0.18 €$ to $0.14 €$ when we average across all individuals. Only the increase in $\mathrm{WTP}_{\text {premium }}$ for conventional chocolate choosers is significant, while the decrease which we observe for Fairtrade choosers is not, as is confirmed by non-parametric tests reported below and illustrated by boxplots in Figure 2. While there is some downward shift in $\mathrm{WTP}_{\text {premium }}$ for the Fairtrade choosers, the median and upper and lower quartiles are hardly affected. In contrast, $\mathrm{WTP}_{\text {premium }}$ for the conventional choosers is shifted upward substantially.

Table 2 presents results from an OLS regression of the Fairtrade premium on dummies for the public treatment and whether the subject had chosen Fairtrade chocolate (FTchoice) before coming to the experiment as well as the subject's earnings from the market game 

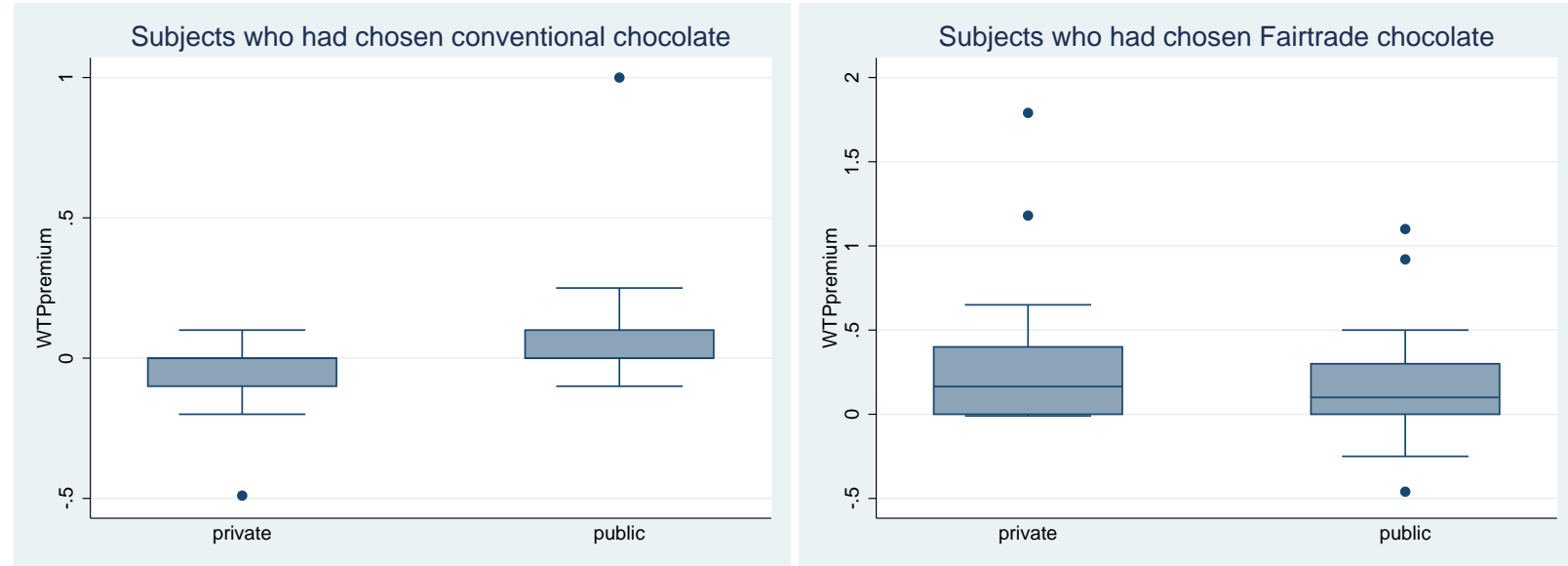

Figure 2: Boxplots of distribution of WTPpremium by treatment. Left panel: conventional choosers, right panel: Fairtrade choosers.

in the first part of the experiment (marketprofit). We also include the interaction effects between the two dummies and between (marketprofit) and the treatment dummy.

Looking at all 121 individuals, we find the following results (see Table 2, column 1). Our treatment dummy public is significant $(+29.2$ Cents, $p=0.018)$ implying that making choices public increases individuals' willingness to pay a premium for Fairtrade chocolate. Thus, we empirically confirm the relevance of image concerns in Fairtrade consumption. As expected, having chosen Fairtrade chocolate before the experiment is associated with a significantly higher $\mathrm{WTP}_{\text {premium }}(+31.3$ Cents, $p<0.001)$. Higher earnings in the first stage also increase $\mathrm{WTP}_{\text {premium }}$; the effect is marginally significant (coefficient of 0.007, i.e. +0.7 Cents per $1 €$ higher income, $p=0.056)$. The interaction between first stage profits and public is significantly negative with a coefficient of $-0.012(p=0.047)$. This implies that in the public treatment, first stage profits have no significant effect. We confirm this in a separate regression conditioning on the treatment being public, where the coefficient of first stage profits is insignificant $(p>0.1) .{ }^{14}$ Whereas the significance of income is not surprising as it illustrates a simple income effect, ${ }^{15}$ at a first glance the irrelevance of income in the public treatment is. Since income from the market game was higher if an individual behaved more unfairly, we believe that individuals with high profits shy away

${ }^{14}$ Table 6 (in the Appendix), column 1 illustrates that within the subsample of participants whose chocolate choice was elicited in public at the cafeteria or library, the choice of Fairtrade chocolate is not significantly correlated with the willingness to pay a premium for Fairtrade in the experiment in contrast to the sample of individuals who chose via email. Columns 2 and 3 in Table 6 and Table 7 (also in the Appendix) show that results in the cafeteria/library subsample are far from robust.

${ }^{15}$ Indeed in the private treatment both $\mathrm{WTP}_{\text {fair }}$ and $\mathrm{WTP}_{\text {conv }}$ increase with the income from the first part of the experiment. 
from increasing their willingness to pay in the public treatment so that they do not reveal their unfair behavior.

The descriptive analysis points to important heterogeneity between the two groups, those that have chosen conventional chocolate and those who have chosen Fairtrade chocolate before the experiment. This heterogeneity shows up significantly in the regression analysis (see Table 2, column 1). The interaction effect between having chosen Fairtrade chocolate and public is significant with a $p$-value of 0.016 . The coefficient on the interaction is negative and with -0.290 similar in size to the aggregate treatment effect. Thus, in our experiment, image concerns are significantly less pronounced and virtually absent for those individuals who had chosen the Fairtrade chocolate. In fact, making choices public has a significant effect on the willingness to pay a premium for Fairtrade only for those who had chosen conventional chocolate if we control for first-stage profits. ${ }^{16}$

Our main results remain qualitatively unchanged if we exclude 18 individuals with "no demand", i.e., individuals who state a willingness to pay of less than 2 cents for each of the two types of chocolate (see Table 2, column 2). The main difference is that the profit from the first part would not have a significant impact anymore (and the interaction effect with the treatment dummy only at the $10 \%$ level). Furthermore, one could worry that the interaction in the first part of the experiment may have influenced the participants and hence conclude that one should not consider individual Fairtrade premia as independent observations. Clustering standard errors on the group level (with 36 independent groups) yields slightly smaller $p$-values for the treatment dummy and the interaction effect with the FTchoice dummy, but now marketprofit is not significant anymore $(p=0.193)$ and marketprofit* public is only significant at the $10 \%$ level (see Table 2, columns 3 and 4 for details). Alternatively, we also run the regression with group-level random effects, which has no effect on significance levels (the $p$-values all become marginally smaller, see Table 2 , columns 5 and 6 for details).

We also ran probit regressions for a dummy of having a positive Fairtrade premium and the independent variables as above. Unsurprisingly, those having chosen Fairtrade before the experiment are significantly more likely to have a positive Fairtrade premium

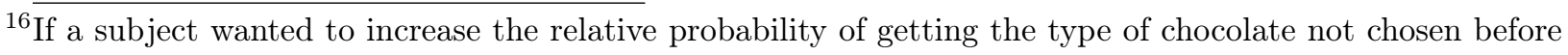
the experiment, she would increase her premium as a conventional chooser and decrease it as a Fairtrade chooser. However, willingness-to-pay for Fairtrade chocolate is higher for Fairtrade choosers and higher for conventional chocolate for conventional chocolate choosers, see Figure 1. Moreover, such balancing or hedging behavior cannot explain the heterogeneity in the treatment effect. Furthermore, remember that we distributed milk chocolate for participating and dark chocolate in the second part of the experiment, so that getting twice the same chocolate was excluded by design. 


\begin{tabular}{lcccccc}
\hline WTP & \multicolumn{2}{c}{ Standard } & \multicolumn{2}{c}{ Clustered SE } & \multicolumn{2}{c}{ Group-level RE } \\
& $(1)$ & $(2)$ & $(3)$ & $(4)$ & $(5)$ & $(6)$ \\
\hline FTchoice & $0.313^{* * *}$ & $0.341^{* * *}$ & $0.313^{* * *}$ & $0.341^{* * *}$ & $0.313^{* * *}$ & $0.335^{* * *}$ \\
& $(0.085)$ & $(0.094)$ & $(0.060)$ & $(0.060)$ & $(0.085)$ & $(0.093)$ \\
public & $0.292^{* *}$ & $0.311^{* *}$ & $0.292^{* *}$ & $0.311^{* *}$ & $0.292^{* *}$ & $0.284^{* *}$ \\
& $(0.122)$ & $(0.134)$ & $(0.109)$ & $(0.115)$ & $(0.122)$ & $(0.138)$ \\
FTchoice* public & $-0.290^{* *}$ & $-0.283^{* *}$ & $-0.290^{* * *}$ & $-0.283^{* *}$ & $-0.290^{* *}$ & $-0.236^{*}$ \\
& $(0.119)$ & $(0.132)$ & $(0.106)$ & $(0.113)$ & $(0.119)$ & $(0.133)$ \\
marketprofit & $0.007^{*}$ & 0.006 & 0.007 & 0.006 & $0.007^{*}$ & 0.006 \\
& $(0.004)$ & $(0.004)$ & $(0.005)$ & $(0.005)$ & $(0.004)$ & $(0.004)$ \\
marketprofit*public & $-0.012^{* *}$ & $-0.012^{*}$ & $-0.012^{*}$ & $-0.012^{*}$ & $-0.012^{* *}$ & $-0.011^{*}$ \\
& $(0.006)$ & $(0.007)$ & $(0.006)$ & $(0.007)$ & $(0.006)$ & $(0.007)$ \\
\hline Observations & 121 & 103 & 121 & 103 & 121 & 103 \\
$\mathrm{R}^{2}$ & 0.150 & 0.158 & 0.150 & 0.158 & $(\mathrm{a})$ & $(\mathrm{b})$ \\
Prob $>\mathrm{F}$ & 0.002 & 0.005 & 0.000 & 0.000 & 0.001 & 0.002 \\
\hline
\end{tabular}

${ }^{*} p<0.10,{ }^{* *} p<0.05,{ }^{* * *} p<0.01$

Table 2: Regression of $\mathrm{WTP}_{\text {premium }}$ on (ex ante) Fairtrade choice, profits from the first part of the experiment, treatment (public) and interaction terms. Columns 1 and 2 are the benchmark specifications for all subjects who made their chocolate choice via email. Columns 3 and 4 account for standard errors clustering at the group level, columns 5 and 6 include group-level random effects. In columns 2, 4, and 6 we exclude subjects who bid less than 2 cents for each type of chocolate. Standard errors in parentheses. (a) $R^{2}$ : within $=0.1391$, between $=0.1217$, overall $=0.1503$. (b) $\mathrm{R}^{2}$ : within $=0.2204$, between $=0.0022$, overall $=0.1563$ 
$(p<0.01)$, the treatment effect is significantly positive $(p<0.10)$ and the interaction effect between these dummies is negative and significant $(p<0.05)$, the results being again robust to including group-level random effects (see Table 5 in the Appendix). ${ }^{17}$ Thus, we can see two things from the probits. First, in the private treatment, those who choose conventional chocolate before the experiment are significantly less likely to have a positive Fairtrade premium than those who have chosen Fairtrade before. Second, in the public treatment, the conventional choosers become significantly more likely to state a positive Fairtrade premium. While only one out of 13 in the private treatment states a positive Fairtrade premium, seven out of 15 in the public treatment do so. While these results are in

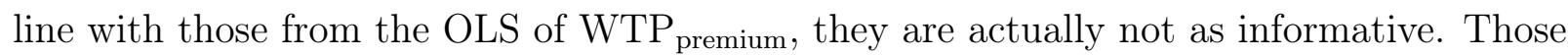
choosing Fairtrade before the experiment should already have a positive Fairtrade premium in the private treatment (and 33 out of 42 do, ignoring subjects who state a maximum WTP smaller than $0.02 €$ ) and hence the treatment cannot have much of an effect in this group, hence the negative interaction effect (26 out of 34 state a positive Fairtrade premium in the public treatment). In the OLS, we could also observe if Fairtrade choosers react to the image building opportunities by increasing their Fairtrade premium but see that they do not.

The results regarding the heterogeneity of image concerns are also confirmed by nonparametric Mann-Whitney tests. ${ }^{18}$ The Fairtrade premium is significantly larger in the public than in the private treatment for those subjects who had chosen conventional chocolate $(p=0.005)$, but not for those who had chosen Fairtrade chocolate $(p=0.122)$. Furthermore, the Fairtrade premium in the private treatment is significantly larger for those who had chosen Fairtrade chocolate than for those who had chosen conventional chocolate $(p<0.001)$, but in the public treatment the Fairtrade premium does not differ significantly between these two groups $(p=0.123)$. This is in line with the regression results in sug-

${ }^{17}$ One participant, a Fairtrade chooser in the public treatment, stated after the experiment to have accidentally swapped $\mathrm{WTP}_{\text {fair }}$ and $\mathrm{WTP}_{\text {conv }}$. The aggregate data and statistical analysis reported in this paper use the original data as he entered them, because some participants always make mistakes and it seems somewhat arbitrary to correct those that some participants report later to be mistakes. Nevertheless, we also performed robustness checks with the WTPs as he claimed he had wanted to enter them. The only difference we observe regarding the treatment and the proxy for the intrinsic preference is that in the probit regression, when we exclude participants with a maximum $\mathrm{WTP}<0.02 €$, then in the uncorrected data, the treatment dummy is significant at $10 \%$, but just misses significance at the $10 \%$ level in the corrected data. In addition, the significance of the impact of the profits from the first part is weaker in some of the regressions, but the impact of the profit is not our concern.

${ }^{18}$ The caveat that these tests uses individual Fairtrade premia as independent observation applies here again. But since it is not obvious how interaction in the market stage should have impacted on the decisions here and taking the dependence into account did not make a difference in the regressions, we consider these tests valid at least as additional support. 
gesting that opportunities for image building lead those not intrinsically motivated to pool their image with those who are intrinsically motivated, but leaves the latter unaffected.

\section{Concluding discussion}

We have addressed the heterogeneity in image concerns by studying the effect of opportunities for image building on Fairtrade premia for experimental participants with different intrinsic motivation. We find that participants with low intrinsic motivation to buy Fairtrade react positively to image building opportunities, whereas those with high intrinsic motivation do not.

Our results imply that addressing the signaling desire of consumers who are not sufficiently intrinsically motivated to buy Fairtrade can increase Fairtrade consumption without having to fear an image-based crowding out of intrinsically motivated buyers. Since the intrinsically motivated subjects in our experiment are not influenced by social image building opportunities, they would not be affected if the derived image is diluted because those not intrinsically motivated are encouraged by extrinsic incentives (such as image building opportunities but also, e.g., material rewards) to buy the same products. Hence extrinsic incentives are not likely to crowd out intrinsic motivation in our setting.

On the aggregate level, for the Fairtrade choosers we even observe a decrease of the Fairtrade premium in the public treatment. This could be seen as a suggestion that these subjects choose Fairtrade to support their self-image and that the expected pooling of those only driven by social image in the public treatment leads to a decrease of the selfimage derived from the stated Fairtrade premium and hence their Fairtrade premium actually decreases if self-image is derived as if in the eye of a neutral observer as in the model by Bénabou and Tirole (2003). ${ }^{19}$ However, such motivations do not seem to play a role because once we control for the profits from the first part of the experiment, the treatment effect on the Fairtrade choosers completely disappears. In an OLS regression of the Fairtrade premium restricted to the subjects who chose Fairtrade before the experiment,

\footnotetext{
${ }^{19}$ Alternatively, one could also imagine that some people perceive a negative image of appearing to want to have a positive image. This second-order stigma of first-order image concerns could then lead some intrinsically motivated participants to have a lower Fairtrade premium in the public treatment, because even though they can now derive social image from the Fairtrade choice they might care more about the stigma attached to being concerned with that image. In equilibrium, heterogeneity in concerns for stigma is required (and it has to be rare) because otherwise no positive image could be derived from a positive Fairtrade premium in the first place.
} 
the coefficient on the dummy for the public treatment is actually positive, but very small and very far from being significantly different from zero $(p>0.8) .{ }^{20}$

In our study, the positive effect on the fairtrade premium of the conventional choosers is mostly driven by an increase in their willingness-to-pay for Fairtrade chocolate. This is in contrast to findings by Teyssier et al. (2012) who find an increase in the Fairtrade premium driven by a decrease in the willingness-to-pay for conventional chocolate. One possible explanation for this difference might have to do with the way subjects perceive the public situation. Do they get a boost in utility from a positive image and therefore increase their willingness-to-pay for Fairtrade or do they respond to social pressure which decreases their utility from conventional chocolate? Whereas the results by Teyssier et al. (2012) seem to indicate that the latter is the case and therefore making choices public may decrease consumer surplus, our results point into the opposite direction.

Our results that those not intrinsically motivated care for social image but the intrinsically motivated do not, would also suggest that the profit maximizing strategy of a monopolist will attempt to pool consumers who intrinsically value Fairtrade with those who only care about their image. Thus only one type of "ethical" good should be offered. Alternatively, if a subset of the intrinsically motivated cared substantially about social image, it would pay for the producer to offer a high-quality (where quality here refers to the quality in the ethical dimension) high-price product for them to allow them to separate from those purely interested in social image, who in turn are pooled on an intermediatequality intermediate-price product with those who are only intrinsically motivated, but not through social image (see Friedrichsen (2013) for these theoretical results). Our results are thus in contrast with the propagation of Fairtrade labels that differ in the strictness of their standards, which suggests separation. Naturally, other components may matter here as well, including heterogeneity in the sensitivity to price as a signal of quality and in the information about the different standards (such that product differentiation would not be derived from heterogeneity in image concerns and quality preferences but from incomplete information).

As always, care should be applied when deriving conclusions from our experiment. There are several perceivable alternative explanations for our results. If a positive image can be realized by revealing a positive Fairtrade premium but does not further improve in the size of the premium, the fact that Fairtrade choosers do not increase their Fairtrade

\footnotetext{
${ }^{20}$ Table 4 in the Appendix shows results from regressions on the two subsamples of individuals who chose conventional and Fairtrade chocolate, respectively. Only for those who chose conventional chocolate the treatment effect is significant.
} 
premium is not informative about their image concerns. However, if this was the case the Fairtrade premium should cluster at a very low positive level which it does not. Another possible argument is that for Fairtrade choosers the increase in image from separating compared to pooling with the conventional choosers could be small, such that the Fairtrade choosers would not find it worthwhile to increase their Fairtrade premium to achieve separation (for example, because relatively few conventional choosers would pool with them, which would hence not dilute the image much). Again, the variance in observed positive Fairtrade premia speaks against this hypothesis. Finally, some participants might see a public good character in Fairtrade but decide to free-ride in private. In public, however, they decide to contribute and thereby give an example to others who might follow them and contribute in the future. Note that our experiment is one shot so that such future contributions would have to happen outside the lab.

Moreover, even if our interpretation is correct, we only considered one very specific setting, with a specific group of participants (almost exclusively university students). We see our contribution therefore as demonstrating that indeed important types of heterogeneity in image concerns do exist, in contrast to the approach taken traditionally in the literature on conspicuous consumption and thus that it is important to take this heterogeneity into account in economic modeling as well as policy recommendations. In contrast, it would be premature to generalize our results to suggest that the intrinsically motivated are in general not concerned with social image.

Our results are, however, also in line with and help better understand other empirical and experimental results that point to important heterogeneity. Charles et al. (2009) find that visible expenditures are higher in poorer groups, which have a stronger need to signal their status, than in richer groups. This also indicates a negative correlation between the wealth to be signaled and the desire to signal. Furthermore, two survey studies point to interaction effects between intrinsic motivation and image concerns in the context of ethical consumption (Vermeir and Verbeke, 2006; Bellows et al., 2008). In a telephone survey by Bellows et al. (2008), conducted in the US, a significant share of people report to strongly value organic production systems but not to buy organic products. Furthermore, some state that they do not value organic production methods but report high probabilities of buying organic produce. The effects correlate with demographic characteristics and could be explained by a signaling concern which induces higher educated and richer individuals 
to spend more on organic goods. ${ }^{21}$ Using a survey combined with an experiment, Vermeir and Verbeke (2006) describe a consumer type who buys a sustainable product despite reporting a rather negative attitude towards it. These consumers state that friends and family of theirs put high importance on their purchasing behavior. Since reacting to others' norms is just another facette of image concerns, this finding gives further empirical backing for heterogeneous image concerns in sustainable consumption. However, the experimental design of Vermeir and Verbeke (2006) is not suited to illuminate how intrinsic motivation and image concerns interact with each other. Our results are also in line with a result in a study by Filippin et al. (2013) on tax morale. In this case, social reputation (for withholding taxes) is negative (stigma). The authors find that those intrinsically motivated are less affected by this negative social reputation, in line with our results.

Regarding experimental studies, two articles point to relevant heterogeneity in image concerns. Grossman (2010) finds more compelling evidence for social signaling concerns if he excludes "selfish-types" and "money-maximizers", indicating a positive relation between image motivation and intrinsic giving in his sample, opposite to what we find. The findings by Lazear et al. (2012) reported above (see Section 2) would be consistent with a negative correlation between image concerns and intrinsic motivation to give. However, the paper does not offer sufficient information on the data to check this.

Finally, our experimental design delivers a methodological insight. While a random price mechanism may be problematic for eliciting willingness to pay and especially willingness to accept because of possible misconceptions of the mechanism (Plott and Zeiler, 2005; Cason and Plott, 2012), this is less of a concern in our analysis. First of all, the mechanism is more robust for the elicitation of differences in willingness to pay (or accept), such as the Fairtrade premium that we elicit in our experiment. The reason is that any misconceptions that simply lead to a shift of the elicited WTP would influence both WTPs equally and hence be canceled out in the difference. Moreover, we are only really interested in differences in the Fairtrade premium and the effect of any misconceptions on the WTPs can well cancel out in these differences-in-differences. Most importantly, our main research questions do not rely on the absolute level and hence on precise measures of WTP or the Fairtrade premium or even of differences or differences-in-differences in the Fairtrade premium, but on whether the Fairtrade premium differs significantly across treatments or across groups of participants and whether the difference across treatments differs

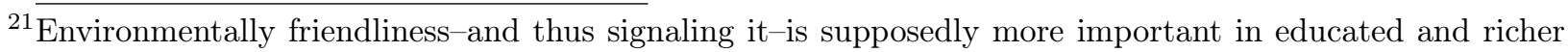
groups. Consistent with this result, Charles et al. (2009) find that within reference groups, richer individuals signal more. 
between the two groups of participants. Thus the crucial hypotheses rely on whether the differences and differences-in-differences in the Fairtrade premia are significantly different from zero, not on their precise magnitude. Our conclusions are therefore robust to any misconceptions that lead to a bias that results in a monotone transformation of true into stated WTP, such as the perception as a first-price auction that appears to occur in Cason and Plott (2012), as long as the bias is not systematically related to the treatment. One could imagine further misconceptions, but it appears that in order to test hypotheses relying on whether differences (and differences-in-differences and diffs-in-diffs-in-diffs) in WTP are significant, the random price mechanism is substantially more robust to misconceptions than when it is used to measure WTP. 


\section{References}

Andreoni, J. and Bernheim, B. D. (2009). Social Image and the 50-50 Norm: A Theoretical and Experimental Analysis of Audience Effects. Econometrica, 77 (5), 1607-1636.

Ariely, D., Bracha, A. and Meier, S. (2009). Doing Good or Doing Well? Image Motivation and Monetary Incentives in Behaving Prosocially. American Economic Review, 99 (1), 544-555.

Bagwell, L. S. and Bernheim, B. D. (1996). Veblen Effects in a Theory of Conspicuous Consumption. American Economic Review, 86 (3), 349-373.

Becker, G., DeGroot, M. and Marschak, J. (1964). Measuring Utility by a SingleResponse Sequential Method. Behavioral Science, 9 (3), 226-232.

Bellows, A. C., Onyango, B., Diamon, A. and Hallman, W. K. (2008). Understanding Consumer Interest in Organics: Production Values vs. Purchasing Behavior. Journal of Agricultural \&6 Food Industrial Organization, 6 (2), 1-28.

Bénabou, R. and Tirole, J. (2003). Intrinsic and Extrinsic Motivation. Review of Economic Studies, 70 (3), 489--520.

Bénabou, R. and Tirole, J. (2006). Incentives and Prosocial Behavior. American Economic Review, 96 (5), 1652-1678.

Carpenter, J. and Myers, C. K. (2010). Why Volunteer? Evidence on the Role of Altruism, Image, and Incentives. Journal of Public Economics, 94 (11-12), 911-920.

Cason, T. N. and Plott, C. R. (2012). Misconceptions and Game Form Recognition of the BDM Method: Challenges to Theories of Revealed Preference and Framing. Mimeo, Purdue University.

Chao, A. and Schor, J. B. (1998). Empirical Tests of Status Consumption: Evidence from Women's Cosmetics. Journal of Economic Psychology, 19 (1), 107-131.

Charles, K. K., Hurst, E. and Roussanov, N. (2009). Conspicuous Consumption and Race. Quarterly Journal of Economics, 124 (2), 425-467.

Dana, J., Cain, D. M. and Dawes, R. M. (2006). What You Don't Know Won't Hurt Me: Costly (but Quiet) Exit in Dictator Games. Organizational Behavior and Human Decision Processes, 100, 193-201.

Danz, D., Engelmann, D., Friedrichsen, J. and Kübler, D. (2013). Fair Behavior in Experimental Markets and Consumption Decisions. In preparation.

- - — and KüBler, D. (2012). Do Legal Standards Affect Ethical Concerns of Consumers? An Experiment on Minimum Wages. University of Mannheim Working Paper Series, No. $12-3$. 
De FrajA, G. (2009). The Origin of Utility: Sexual Selection and Conspicuous Consumption. Journal of Economic Behavior \& Organization, 72 (1), 51-69.

DellaVigna, S., List, J. A. and Malmendier, U. (2012). Testing for Altruism and Social Pressure in Charitable Giving. Quarterly Journal of Economics, 127 (1), 1-56.

Filippin, A., Fiorio, C. V. and Viviano, E. (2013). The Effect of Tax Enforcement on Tax Morale. European Journal of Political Economy, 32, 320-331.

FischBACHER, U. (2007). Zurich Toolbox for Ready-made Economic Experiments. Experimental Economics, 10 (2), 171-178.

Frackenpohl, G. and Pönitzsch, G. (2013). Bundling Public with Private Goods. Bonn Econ Discussion Papers, No. 05/2013, University of Bonn.

Friedrichsen, J. (2013). Image Concerns and the Provision of Quality. WZB Discussion Paper SP II 2013-211, Berlin: WZB.

Gneezy, U. and Rustichini, A. (2000). Pay Enough or Don't Pay at All. Quarterly Journal of Economics, 115 (3), 791-810.

Greiner, B. (2004). An Online Recruitment System for Economic Experiments. In K. Kremer and V. Macho (eds.), Forschung und wissenschaftliches Rechnen 2003. GWDG Bericht 63, Göttingen: Gesellschaft für Wissenschaftliche Datenverarbeitung, pp. 79-93.

Griskevicius, V., Tybur, J. M., Sundie, J. M., Cialdini, R. B., Miller, G. F. and Kenrick, D. T. (2007). Blatant Benevolence and Conspicuous Consumption: When Romantic Motives Elicit Strategic Costly Signals. Journal of Personality and Social Psychology, 93 (1), 85-102.

-, - and Van den Bergh, B. (2010). Going Green to Be Seen: Status, Reputation, and Conspicuous Conservation. Journal of Personality and Social Psychology, 98 (3), 392-404.

Grossman, Z. (2010). Self-Signaling Versus Social-Signaling in Giving. Mimeo, University of California Santa Barbara.

Harbaugh, W. T. (1998a). The Prestige Motive for Making Charitable Transfers. American Economic Review, 88 (2), 277-282.

- (1998b). What Do Donations Buy? A Model of Philanthropy Based on Prestige and Warm Glow. Journal of Public Economics, 67 (2), 269-284.

Heffetz, O. (2011). A Test of Conspicuous Consumption: Visibility and Income Elasticities. Review of Economics and Statistics, 93 (4), 1101-1117. 
Ireland, N. J. (1994). On Limiting the Market for Status Signals. Journal of Public Economics, 53 (1), 91-110.

Koppel, H. and Schulze, G. G. (2013). The Importance of the Indirect Transfer Mechanism for Consumer Willingness to Pay for Fair Trade Products - Evidence from a Natural Field Experiment. Journal of Consumer Policy, 36 (4), 369-387.

Lacetera, N. and Macis, M. (2010). Social Image Concerns and Prosocial Behavior: Field Evidence from a Nonlinear Incentive Scheme. Journal of Economic Behavior and Organization, 76 (2), 225-237.

Lazear, E. P., Malmendier, U. and Weber, R. A. (2012). Sorting in Experiments with Application to Social Preferences. American Economic Journal: Applied Economics, 4 (1), 136-163.

Linardi, S. and MCConnell, M. A. (2011). No Excuses for Good Behavior: Volunteering and the Social Environment. Journal of Public Economics, 95 (5-6), 445-454.

Maynard, M. (2007). Say 'Hybrid' and Many People Will Hear 'Prius'. The New York Times, July 4, 2007.

Miller, G. F. (2000). The Mating Mind: How Sexual Choice Shaped the Evolution of Human Nature. Doubleday.

Pastine, I. and Pastine, T. (2002). Consumption Externalities, Coordination, and Advertising. International Economic Review, 43 (3), 919-943.

Pesendorfer, W. (1995). Design Innovation and Fashion Cycles. American Economic Review, 85 (4), 771-92.

Plott, C. R. and Zeiler, K. (2005). The Willingness to Pay/Willingness to Accept Gap, the "Endowment Effect", Subject Misconceptions and Experimental Procedures for Eliciting Valuations. American Economic Review, 95 (3), 530-545.

Potters, J., Sefton, M. and Vesterlund, L. (2007). Leading-by-Example in Voluntary Contribution Games: An Experimental Study. Economic Theory, 33 (1), 169-182.

Rayo, L. (2013). Monopolistic Signal Provision. The B.E. Journal of Theoretical Economics, 13 (1).

Rege, M. (2008). Why Do People Care about Social Status? Journal of Economic Behavior \& Organization, 66 (2), 233-242.

Seabright, P. (2009). Continuous Preferences and Discontinuous Choices: How Altruists Respond to Incentives Continuous. The B.E. Journal of Theoretical Economics (Contributions), 9 (1). 
Sexton, S. E. and Sexton, A. L. (2011). Conspicuous Conservation: The Prius Effect and Willingness to Pay for Environmental Bona Fides. Mimeo, University of California, Berkeley.

Soetevent, A. R. (2005). Anonymity in Giving in a Natural Context - a Field Experiment in 30 Churches. Journal of Public Economics, 89 (11-12), 2301-2323.

- (2011). Payment Choice, Image Motivation and Contributions to Charity: Evidence from a Field Experiment. American Economic Journal: Economic Policy, 3 (1), 180205.

Strahilevitz, M. and Myers, J. G. (1998). Donations to Charity as Purchase Incentives: How Well They Work May Depend on What You Are Trying to Sell. Journal of Consumer Research, 24 (4), 434-446.

Teyssier, S., Etilé, F. and Combris, P. (2012). Social-and Self-Image Concerns in Fair-Trade Consumption: Evidence from Experimental Auctions for Chocolate. Working Paper No. 2012-33, Paris School of Economics.

Tonin, M. and Vlassopoulos, M. (2013). Experimental Evidence of Self-Image Concerns as Motivation for Giving. Journal of Economic Behavior 83 Organization, 90, $19-27$.

Veblen, T. (1915). The Theory of the Leisure Class: An Economic Study of Institutions. Macmillan.

Vermeir, I. and Verbeke, W. (2006). Sustainable Food Consumption: Exploring the Consumer 'Attitude-Behavioral Intention' Gap. Journal of Agricultural and Environmental Ethics, 19 (2), 169-194.

Vesterlund, L. (2003). The Informational Value of Sequential Fundraising. Journal of Public Economics, 87 (3-4), 627-657. 


\section{A Supplementary material}

\section{A.1 Additional results and figures}

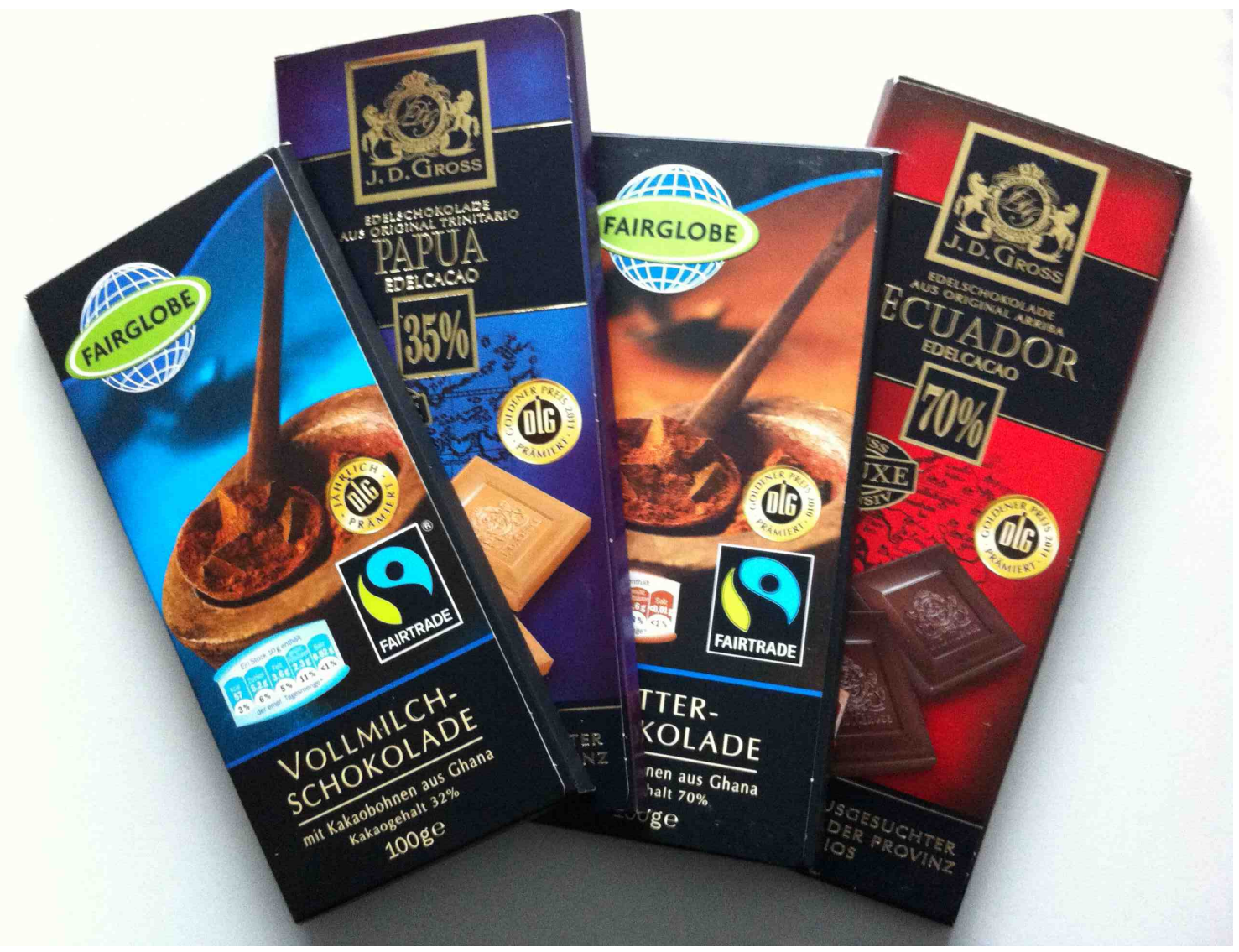

Figure 3: Chocolate used in the experiment. We used milk chocolate to derive a proxy of intrinsic preferences and dark chocolate to elicit willingness to pay. 


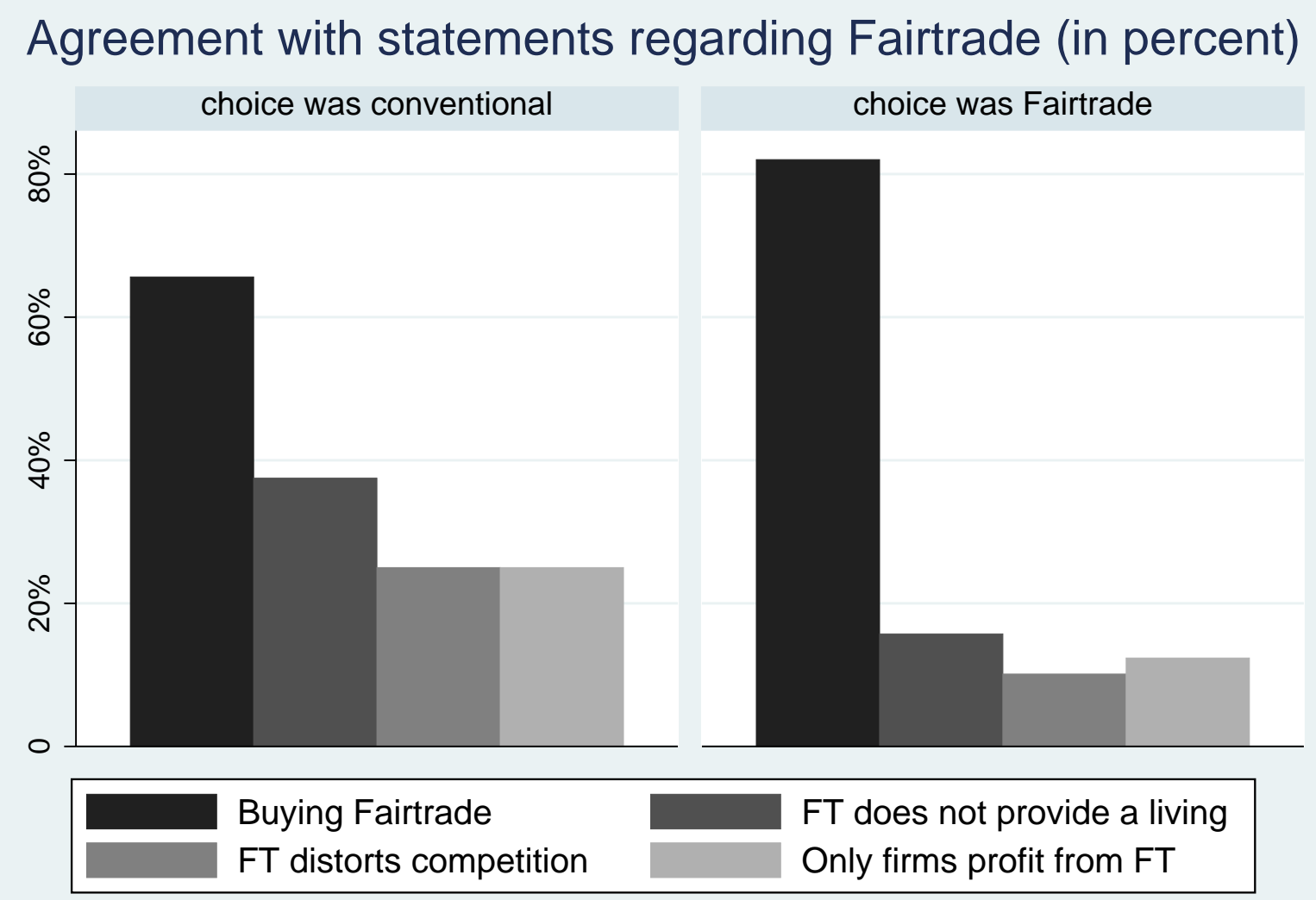

Graphs by FTchoice

Figure 4: The choice of Fairtrade chocolate is associated with a higher frequency of buying Fairtrade and a more positive attitudes towards Fairtrade.

\begin{tabular}{c|cc}
\hline quality tolerance & conventional & Fairtrade \\
\hline 0 & 31 & 82 \\
1 & 1 & 7 \\
\hline FT quality & conventional & Fairtrade \\
\hline 0 & 25 & 46 \\
1 & 7 & 43 \\
\hline
\end{tabular}

Table 3: Quality tolerance takes the value 1 if the respondent chose a strictly positive value as response to the statement: "I am prepared to accept lower quality in FT products" with answer categories "strongly disagree $(-3)$ " to "fully agree $(+3)$ ". FT quality takes the value 1 if the respondent chose a strictly positive value as response to the statement: "Compared to conventional products, the quality of FT products is usually $<>$." with answers categories "much worse $(-3)$ " to "much better $(+3)$ ". 


\begin{tabular}{lcccc}
\hline \multirow{2}{*}{ WTP $_{\text {premium }}$} & \multicolumn{2}{c}{ Fairtrade } & \multicolumn{2}{c}{ Conventional } \\
& $(1)$ & $(2)$ & $(3)$ & $(4)$ \\
& all & pos. demand & all & pos. demand \\
\hline public & 0.014 & 0.059 & $0.258^{* *}$ & $0.267^{* *}$ \\
& $(0.100)$ & $(0.119)$ & $(0.111)$ & $(0.123)$ \\
marketprofit & $0.008^{*}$ & 0.006 & 0.004 & 0.004 \\
& $(0.005)$ & $(0.005)$ & $(0.006)$ & $(0.007)$ \\
marketprofit*public & -0.013 & -0.016 & -0.008 & -0.008 \\
& $(0.009)$ & $(0.010)$ & $(0.008)$ & $(0.009)$ \\
\hline Observations & 89 & 75 & 32 & 28 \\
$\mathrm{R}^{2}$ & 0.071 & 0.054 & 0.182 & 0.194 \\
Prob $>\mathrm{F}$ & 0.098 & 0.264 & 0.126 & 0.152 \\
\hline$* p<0.10 * * *<0.05 * * * p<0.01$ & & &
\end{tabular}

Table 4: Results when we split the sample according to chocolate choice. Column 2 and 4 exclude observations with maximum $\mathrm{WTP}<2$ cents. Standard errors in parentheses. 


\begin{tabular}{|c|c|c|c|c|}
\hline \multirow{3}{*}{$\mathrm{WTP}_{\text {premium }}>0$} & \multicolumn{2}{|c|}{ Probit } & \multicolumn{2}{|c|}{ Probit with RE } \\
\hline & (1) & (2) & (3) & \\
\hline & all & pos. demand & all & pos. demand \\
\hline FTchoice & $\begin{array}{c}2.042^{* * *} \\
(0.544)\end{array}$ & $\begin{array}{c}2.302^{* * * *} \\
(0.577)\end{array}$ & $\begin{array}{c}2.048^{* * *} \\
(0.570)\end{array}$ & $\begin{array}{c}2.302^{* * *} \\
(0.577)\end{array}$ \\
\hline public & $\begin{array}{l}1.275^{*} \\
(0.667)\end{array}$ & $\begin{array}{l}1.244^{*} \\
(0.690)\end{array}$ & $\begin{array}{l}1.278^{*} \\
(0.674)\end{array}$ & $\begin{array}{l}1.244^{*} \\
(0.690)\end{array}$ \\
\hline FTchoice*public & $\begin{array}{c}-1.535^{* *} \\
(0.661)\end{array}$ & $\begin{array}{c}-1.533^{* *} \\
(0.707)\end{array}$ & $\begin{array}{c}-1.539^{* *} \\
(0.674)\end{array}$ & $\begin{array}{c}-1.533^{* *} \\
(0.707)\end{array}$ \\
\hline marketprofit & $\begin{array}{l}-0.001 \\
(0.019)\end{array}$ & $\begin{array}{l}-0.020 \\
(0.020)\end{array}$ & $\begin{array}{l}-0.001 \\
(0.019)\end{array}$ & $\begin{array}{l}-0.020 \\
(0.020)\end{array}$ \\
\hline marketprofit* public & $\begin{array}{l}-0.007 \\
(0.028)\end{array}$ & $\begin{array}{c}0.015 \\
(0.032)\end{array}$ & $\begin{array}{l}-0.007 \\
(0.029)\end{array}$ & $\begin{array}{c}0.015 \\
(0.032)\end{array}$ \\
\hline Observations & 121 & 103 & 121 & 103 \\
\hline Pseudo $\mathrm{R}^{2}$ & 0.1365 & 0.2050 & - & - \\
\hline Prob $>$ F & 0.000 & 0.000 & 0.008 & 0.001 \\
\hline
\end{tabular}

Table 5: Probit model: Dependent variable is 1 if the willingness to pay a premium for Fairtrade is positive (i.e. $\mathrm{WTP}_{\text {Fair }}>\mathrm{WTP}_{\text {conventional }}$ ). Column 2 and 4 exclude observations with maximum $\mathrm{WTP}<2$ cents. Column 3 and 4 include group-level random effects. Standard errors in parentheses. 


\begin{tabular}{lccc}
\hline & $(1)$ & $(2)$ & $(3)$ \\
WTP $_{\text {premium }}$ & Standard & Group-level RE & Clustered SE \\
\hline FTchoice & 0.214 & $0.312^{* * *}$ & 0.214 \\
& $(0.192)$ & $(0.101)$ & $(0.203)$ \\
public & -0.342 & -0.094 & $-0.342^{*}$ \\
& $(0.219)$ & $(0.192)$ & $(0.174)$ \\
FTchoice*public & 0.054 & -0.220 & 0.054 \\
& $(0.275)$ & $(0.193)$ & $(0.267)$ \\
marketprofit & -0.018 & $-0.024^{* * *}$ & $-0.018^{* *}$ \\
& $(0.012)$ & $(0.006)$ & $(0.008)$ \\
marketprofit*public & $0.029 *$ & $0.031^{* * *}$ & $0.029^{* *}$ \\
& $(0.015)$ & $(0.011)$ & $(0.012)$ \\
\hline Observations & 23 & 23 & 23 \\
$\mathrm{R}^{2}$ & 0.299 & $(\mathrm{a})$ & 0.299 \\
Prob $>\mathrm{F}$ & 0.256 & 0.000 & 0.074 \\
\hline$* p<0.10 * * p<0.05, * * *$ & $p<0.01$ & &
\end{tabular}

Table 6: Accounting for group structure in the subsample of subjects who made chocolate choice (proxy) in public: Column 2 includes group-level random effects, column 3 accounts for standard errors clustering at the group level. (a) $\mathrm{R}^{2}$ : within $=0.8467$, between $=0.1442$, overall $=0.2151$. Standard errors in parentheses. 


\begin{tabular}{lcc}
\hline & $(1)$ & $(2)$ \\
$\mathrm{WTP}_{\text {premium }}>0$ & Probit & Probit with RE \\
\hline none & & \\
FTchoice & -0.097 & -0.996 \\
& $(0.844)$ & $(3.622)$ \\
public & -4.063 & $(13.565)$ \\
FTchoice*public & 0.713 & 5.096 \\
& $(1.708)$ & $(7.764)$ \\
marketprofit & -0.078 & -0.638 \\
& $(0.065)$ & $(0.504)$ \\
marketprofit*public & 0.794 & $5.133^{*}$ \\
& $(0.578)$ & $(2.805)$ \\
\hline Observations & 23 & 23 \\
Pseudo R & 0.3765 & - \\
Prob $>\mathrm{F}$ & 0.048 & 0.494 \\
\hline$* p<0.10,{ }^{* *} p<0.05, * * * p<0.01$ &
\end{tabular}

Table 7: Probit model for the subsample of subjects who made chocolate choice (proxy) in public: Dependent variable is 1 if the willingness to pay a premium for Fairtrade is positive (i.e. $\left.\mathrm{WTP}_{\text {Fair }}>\mathrm{WTP}_{\text {conventional }}\right)$. Column 2 includes group-level random effects. 


\section{A.2 Instructions for the second part of the experiment}

Below is the English translation of original instructions for the second part of the experiment, which were in German. The instructions for the market game (first part of the experiment) are omitted as we do not analyze that part of the experiment here. The instructions for the two treatments only differed in the last paragraph as indicated.

\section{Instructions for the second part of the experiment}

In the second part of the experiment, you make two simple decisions and answer a brief questionnaire.

For the second part of the experiment, you get $4 €$ in addition to your earnings from the first part. You can spend part of these $4 €$ to purchase a bar of chocolate.

\section{Purchase of chocolate}

The potential purchasing of chocolate takes place according to the following mechanism:

- There are two types of chocolate, one is Fairtrade, the other one conventional. Both will be shown to you before you make your decision.

- Please state your maximal willingness-to-pay for each type of chocolate on the screen. Your willingness-to-pay must lie between $0 €$ and $2 €$ and you can choose any amount in Cents in this interval.

- Only your willingness-to-pay for one of the two types of chocolate will be payoffrelevant in the end. Thus, you will get at most one bar of chocolate. The relevant type of chocolate is determined randomly and you will learn only after you have made your decisions which one it is. The same type of chocolate is payoff-relevant for all participants.

- Before it has been determined which type of chocolate is payoff-relevant, the price for the chocolate bar is drawn at random. This price is the same for all participants and is independent of the type of chocolate. The price can be between $0 €$ and $2 €$ and any amount in Cents is equally likely.

- If your stated maximal willingness-to-pay for the relevant type of chocolate is at least as high as the randomly drawn price, you obtain one bar of this type of chocolate and the price is subtracted from the $4 €$ that you were endowed with for the second part of the experiment. If your stated maximal willingness-to-pay is lower than the randomly drawn price, you will not get a bar of chocolate and you do not pay anything; thus you keep your $4 €$.

Please note that with your stated willingness-to-pay you cannot influence the price of the chocolate but only whether you will get a bar. Therefore, you should indeed state how much you would pay at most for the respective type of chocolate. Then you get the chocolate when-ever you do not have to pay more for it than what you are at most willing to pay and you do not get a chocolate whenever you would have to pay more than your maximal willingness-to-pay. 
Example 1: You state a maximal WTP of $0.13 €$ for Fairtrade chocolate and of $1.93 €$ for conventional chocolate. Suppose the randomly determined price is $0.78 €$. If Fairtrade is drawn to be payoff-relevant, you obtain $4 €$ but no chocolate bar because your stated maximal willingness-to-pay of $0.13 €$ is lower than the price of $0.78 €$. If the conventional chocolate is chosen to be payoff-relevant instead, you get a bar of conventional chocolate and you pay $0.78 €$. In this case, you will get $4 €-0.78 €=3.22 €$ and a bar of conventional chocolate for this part of the experiment.

Example 2: You state a maximal WTP of $1.34 €$ for Fairtrade and of $0.62 €$ for conventional chocolate. Suppose the randomly determined price is $0.44 €$. If Fairtrade is chosen to be payoff-relevant, you get a bar of Fairtrade chocolate and you pay $0.44 €$. In this case, you obtain $4 €-0.44 €=3.56 €$ and a bar of Fairtrade chocolate for this part of the experiment. If the conventional chocolate is chosen to be payoff-relevant instead, you get a bar of conventional chocolate and you pay $0.44 €$. In this case, you obtain $4 €-$ $0.44 €=3.56 €$ and a bar of conventional chocolate for this part of the experiment.

From the examples you see that you cannot influence the price through your stated maxi-mal willingness-to-pay (in example 2, you pay the same price in both cases even though the maximal willingness-to-pay is different) but only whether you obtain a bar of chocolate (example 1).

\section{Questionnaire}

After all participants have entered their willingness-to-pay for both types of chocolate, we ask you to fill in a brief questionnaire on the screen.

Distribution of chocolate (private treatment)

After filling in the questionnaire you will first be informed about the randomly drawn price and be reminded of your stated willingness-to-pay for both types. You will then be informed which type of chocolate is payoff-relevant and whether you will obtain a bar. At the end of the experiment you receive your chocolate, if you get one, in the adjoining room together with the money that you earned in the experiment. None of the other participants will learn whether you receive a bar of chocolate, your willingness-to-pay for it or how much money you obtain.

\section{Distribution of chocolate (public treatment)}

After filling in the questionnaire you will first be informed about the randomly drawn price and be reminded of your stated willingness-to-pay for both types. Each of you will then be asked individually to announce your stated maximal willingness-to-pay for the both types of chocolate.

You will then be informed which type of chocolate is payoff-relevant and whether you will obtain a bar.

If your stated willingness-to-pay for the payoff-relevant type is at least as high as the price, you will be asked to come forward to pick up your bar of chocolate.

You will receive the money that you earned in the experiment in the adjoining room. None of the other participants will learn how much money you obtain. 